\title{
Maternal Low Levels Of Thyroid Stimulating Hormone (TSH) With Low Birth Weight In Magelang District
}

\author{
Riska Epina Hayu* \\ *Departement of public health, Al-Insyirah School of Health Science \\ DOI: 10.29322/IJSRP.11.05.2021.p11331 \\ http://dx.doi.org/10.29322/IJSRP.11.05.2021.p11331
}

\begin{abstract}
Based on thyroid screening program has been done by the Magelang District Health Office in 2012 it is known that pregnant women who have low levels of TSH 80/443 pregnancies. Low TSH is the result of an overactive thyroid gland or produce excessive thyroid hormones that circulate in the blood causing hyperthyroidism in pregnant women that can adversely affect the fetus one of which is the occurrence of low birth weight babies (LBW. Cases of low birth weight infants in the District Magelang has increased over the last three years ie in the year 2011 as many as $4.44 \%$ of cases, increased in 2012 as much as $5.03 \%$ of cases and by 2013 as many as $6.16 \%$ of cases. Type analytic observational studied with a retrospective cohort study design using data from 443 pregnant women who have data TSH lab results, a group comprised of 80 pregnant women with low TSH (exposed group ) and 363 pregnant women of normal TSH (unexposed group) analysis using chi square test and multiple logistic regression with $95 \%$ confidence level. Statistical tests that have been used are Stata 12. Subjects numbered 443 people, 80 groups of exposed and unexposed 363. Bivariate analysis showed low TSH levels with the incidence of low birth weight was not statistically significant with p-value 1.70 and 0:07 RR 95\% CI (0.99-2.92). Age mother (outer variable) was statistically significant on the incidence of LBW is the p-value is 2.96 and 0:00 RR 95\% CI (1.86-4.72). Statistically, there was no correlation between low TSH levels with LBW in Magelang regency, but a low TSH in pregnant women can lead to 1.70 times the incidence of LBW. Age mother who is outside variables have statistically significant relationship with the incidence of LBW in Magelang District.
\end{abstract}

Keywords: TSH, low birth weight, Maternal

\section{INTRODUCTION}

During pregnancy, maternal physiological changes affect the thyroid status. Thyroid disorders are the second most common endocrine abnormality found during pregnancy. Abnormalities of the thyroid gland in the mother, has a large adverse effects on mother and fetus. Thyroid disease is a disorder that occurs when the thyroid gland produces more or less thyroid hormone than the body needs. Pregnancy causes changes in normal thyroid function but also can cause thyroid disease ${ }^{(1)}$.

Thyroid hormone is essential for normal development of the baby's brain and nervous system. During the first trimester the fetus depends on the mother's supply of thyroid hormones through the placenta. Slightly enlarged thyroid in healthy women during pregnancy, but not enough to be detected by physical examination. An enlarged thyroid feel could be a sign of thyroid disease and should be evaluated. Thyroid problems can be difficult to diagnose in pregnancy due to higher levels of thyroid hormones in the blood, increasing the size of the thyroid, fatigue, and other symptoms common to both pregnancy and thyroid disorders ${ }^{(2)}$.

TSH tests in pregnant women in endemic areas of IDD needs to be done to determine whether there is a thyroid problem in pregnancy. This test detects even a small amount of TSH in the blood and is the most accurate measure of thyroid activity available. TSH below normal or low indicates hyperthyroidism, whereas abnormally high levels of TSH indicate hypothyroidism. However, low TSH levels can also occur in normal pregnancy, especially in the first trimester, due to a small increase in thyroid hormone of HCG. A health care provider doing the first TSH blood test to check how well the thyroid works. TSH test is the most accurate test to diagnose hyperthyroidism and hypothyroidism. TSH test detects even a small amount of TSH in the blood ${ }^{(2)}$.

Hyperthyroidism is a disorder in which the thyroid gland or overactive thyroid gland produces excessive thyroid hormones that circulate in the blood. Hyperthyroidism is treated less or not associated with an increased risk of miscarriage, premature birth, low birth weight, intra-uterine growth retardation, fetal death, maternal hypertension and thyroid storm ${ }^{(3)}$. Magelang district is endemic regions Gaki. The Government through the Ministry of Health gave priority to efforts to control Gaki overcome the impact on vulnerable groups in endemic areas Gaki, namely women of childbearing age, pregnant women and nursing mothers, infants, toddlers and school-age children. Reduction efforts are yosidasi salt consumption and distribution of iodine capsules.

Prevention efforts by providing massive iodine capsules to women of childbearing age and school-age children each year may result in adverse impact, including the discovery of cases of hyperthyroidism in pregnant women. Low TSH levels and mother diagnosed with hyperthyroidism can lead to abortion in the first trimester of pregnancy, premature birth, sometimes causing toxemia, increases neonatal mortality and infant low birth weight (Longcope, 1993). LBW cases in Magelang District has 
increased over the last three years. In 2011 the case of LBW is increased as much as $4.44 \%$ in $2012(5.03 \%)$ and then increased again in 2013 is $6.16 \%$.

This studied aims to determine the relationship of maternal TSH is low with low birth weight.

\section{RESEARCH METHODS}

The design of the research that has been done is a retrospective cohort studied, with a sample of 443 pregnant women. The entire study was conducted in health centers in Magelang District in July 2014, samples were collected based on the inclusion and exclusion criteria. Data collection was assisted by officers at the health center.

Exposed group is pregnant women with low TSH test results $<0.3 \mu \mathrm{lU} / 1$ based on the results of TSH screening of pregnant women conducted by the District Health Office MagelangTahun 2012 and met the inclusion criteria. The group is not exposed pregnant women with normal blood TSH test results 0.3 to $3.61 \mu \mathrm{lU} / 1$ based on the results of TSH screening of pregnant women conducted by the District Health Office Magelang 2012. The dependent variable in this study is the low birth weight (LBW). The independent variable was maternal TSH levels. While the mother's age and parity are outside variables. Data analysis was performed chi-square test for bivariate and logistic regression for multivariable.

\section{RESULTS AND ANALYSIS}

Univariate analysis presents descriptive data includes the number and percentage.

Table 1. The Frequency Distribution of LBW by Independent Variables and External Variables

\begin{tabular}{rlcccccc} 
& & \multicolumn{2}{c}{ LBW } & \multicolumn{2}{c}{ NBW } & \multicolumn{2}{c}{ Total (N=443) } \\
\cline { 2 - 8 } No & \multicolumn{1}{c}{ Variable } & $\mathbf{N}$ & $\mathbf{\%}$ & $\mathbf{N}$ & $\mathbf{\%}$ & $\mathbf{N}$ & \% \\
\hline 1 & TSH Levels & & & & & & \\
& $<0.3$ & 11 & 13.75 & 69 & 86.25 & 80 & 18.06 \\
& $0.3-3.61$ & 27 & 7.44 & 336 & 92.56 & 363 & 81.94 \\
2 & $\begin{array}{l}\text { Maternal age } \\
\text { <20 and >35 Years }\end{array}$ & 15 & 21.74 & 54 & 78.26 & 69 & 15.58 \\
& old & 23 & 6.15 & 351 & 93.85 & 374 & 84.42 \\
& 20-35 Years old & & & & & & \\
3 & Parity & 20 & 12.35 & 144 & 88.89 & 162 & 36.57 \\
& 1 and > 4 & 18 & 6.41 & 261 & 92.88 & 281 & 63.43 \\
\hline
\end{tabular}

The table above displays univariable analysis on each variable in this study that maternal TSH variables (independent variables), maternal age and parity (dependent variable) on the incidence of low birth weight (dependent variable) in Magelang District. LBW cases of mothers with low TSH levels were $11(13.75 \%)$ infants. Case LBW by maternal age <20 and $>35$ years were $15(21.74 \%)$ infants and $20(12: 35 \%)$ infants with low birth weight infants of mothers who had parity 1 and $>4$.

Bivariate analysis using Chi-square (X2) to see the statistical relationship and the strength of the relationship with RR.

Tabel 2. Ratio Risk of Maternal TSH, Age of Mothers and Parity with Incidence of LBW in Magelang District 2012-2013

\begin{tabular}{|c|c|c|c|c|c|c|c|c|c|}
\hline \multirow[t]{2}{*}{ Variabel } & \multicolumn{2}{|c|}{ BBLR } & \multicolumn{2}{|c|}{ Tidak BBLR } & \multicolumn{2}{|c|}{ Jumlah } & \multirow[t]{2}{*}{$P$-value } & \multirow[t]{2}{*}{$\mathbf{R R}$} & \multirow[t]{2}{*}{$95 \% \mathrm{CI}$} \\
\hline & $\mathbf{N}$ & $\%$ & $\mathbf{N}$ & $\%$ & $\mathbf{N}$ & $\%$ & & & \\
\hline \multicolumn{10}{|l|}{ TSH ibu hamil } \\
\hline$<0.3 \mu \mathrm{Ul} / \mathrm{ml}($ Rendah) & 11 & 13.75 & 69 & 86.25 & 80 & 18.06 & & & \\
\hline $0.3-3.61 \mu \mathrm{Ul} / \mathrm{ml}$ (normal) & 27 & 7.44 & 336 & 92.56 & 363 & 81.94 & 0.07 & 1.70 & $0.99-2.92$ \\
\hline \multicolumn{10}{|l|}{ Maternal Age } \\
\hline$<20$ and $>35$ Tahun & 15 & 21.74 & 54 & 78.26 & 69 & 15.58 & & & \\
\hline 20-35 Tahun & 23 & 6.15 & 351 & 93.85 & 374 & 84.42 & 0.00 & 2.96 & $1.86-4.72$ \\
\hline \multicolumn{10}{|l|}{ Parity } \\
\hline 1 and $\geq 4$ & 20 & 12.35 & 144 & 88.89 & 162 & 36.57 & & & \\
\hline 2 and 3 & 18 & 6.41 & 261 & 92.88 & 281 & 63.43 & 0.15 & 1.33 & $0.93-1.91$ \\
\hline
\end{tabular}

Based on the table it can be seen that a low TSH is not statistically associated with the incidence of LBW because pvalue > 0:05 is 0:07. Maternal age (external variable) was statistically associated with the incidence of LBW in Magelang regency with p-value 0:00, CI 1.86-4.72 and RR 2.96, this means that there are 2.96 the risk of low birth weight babies in women with age $<20$ and $>35$.

Multivariable analysis using logistic regression aims to analyze the relationship between an exposure and disease and to determine the independent variables which most influence on the incidence of low birth weight (dependent variable), conducted as a follow-up test a statistically significant bivariate or have a value of $p<0,25$. 
Tabel 3. Multivariable Analysis Results Low TSH levels with the incidence of low birth weight in Magelang District 2012-2013

\begin{tabular}{|c|c|c|c|c|c|c|}
\hline \multirow[t]{2}{*}{ Variabel } & \multicolumn{2}{|r|}{ Model 1} & \multicolumn{2}{|r|}{ Model 2} & \multicolumn{2}{|r|}{ Model 3} \\
\hline & OR & CI $95 \%$ & OR & CI $95 \%$ & OR & CI $95 \%$ \\
\hline TSH Level & 2.00 & $0.93-4.33$ & 2.02 & $0.94-4.35$ & & \\
\hline Maternal Age & 4.11 & $1.93-8.74 * * *$ & 4.27 & $2.09-8.74 * * *$ & 4.24 & $2.08-8.62 * * *$ \\
\hline Parity & 1.12 & $0.54-2.32$ & & & & \\
\hline Pseudo R ${ }^{2}(\%)$ & & 6.67 & & 6.62 & & 5.48 \\
\hline $\begin{array}{l}\text { AIC (Akaike information } \\
\text { criterion) }\end{array}$ & & 250.02 & & 248.12 & & 249.09 \\
\hline
\end{tabular}

Logistic regression analysis model 3 there is only one variable that is the age of the mother who has a p-value of $<0.05$ with OR 4:24 (2.08-8.62). Based on Table, it is known that the model with the value of AIC (Akaike information criterion) is the smallest in model 2 is 248.12 which indicates that model 2 is the model with the complexity and density (fit) the best among other models. In addition, the model 2 has a pseudo $\mathrm{R} 2$ value $=6.62 \%$, which indicates that the model can predict the incidence of LBW 2 was $6.62 \%$. While the remaining $93.38 \%$ predicted by other variables not examined in this study. This means that there are many possible factors that could influence the occurrence of LBW.

\section{DISCUSSION}

This studied initially consisted of 500 pregnant women were examined levels TSH as research subjects, but at the time of implementation of research there are some data that is incomplete and does not meet the criteria that have been defined in this study, so until the end of the study the research subject as many as 443 people 80 pregnant women with the details of the exposed group (low TSH) and 363 non-exposed group (normal TSH). Of the 80 pregnant women with low TSH levels are included 11 infants with low birth weight and 27 cases of maternal LBW with normal TSH levels. This research was conducted in Magelang District conducted using secondary data, the data TSH test results obtained from the Department of Health and BPGAKY baby and the data collected from all health centers in Magelang District.

Magelang district is an area of IDD endemic iodine intervention programs that get iodine in the form of capsules. Excessive iodine consumption or consumed in large quantities in the long term can lead to hyperthyroidism. For that it needs to be checks TSH in pregnant women and women of childbearing age to avoid or prevent the occurrence of diseases caused by disorders of the thyroid. Thyroid disorders are the second most common endocrine abnormality found during pregnancy (4). Excess and deficiency thyroid hormone is a problem in pregnancy, the thyroid gland is overactive and produces work of the thyroid hormone excess can cause hyperthyroidism. Thyroid stimulating hormone (TSH) or thyrotropin, is a glycoprotein that is synthesized and secreted by thyrotropin from the anterior pituitary gland. Under normal or low TSH indicates hyperthyroidism or condition in which a person produces excess thyroid hormone.

Hyperthyroidism in pregnant women may affect their children, one of which is the occurrence of cases of low birth weight. Research conducted by Miller in 1994 that pregnant women with uncontrolled hyperthyroidism during pregnancy may cause the baby's 9.24 time with low birth weight. Low blood levels of TSH indicate the presence of abnormalities in the thyroid gland works too active so that the occurrence of hyperthyroidism. Hyperthyroidism in pregnancy are not getting treatment can increase the risk of miscarriage, premature birth, low birth weight and fetal death ${ }^{(5)}$. In this study, pregnant women with low TSH levels were not statistically associated with the incidence of LBW in Magelang District. The incidence of low birth weight did not show any significant difference between the low TSH group with normal TSH group ${ }^{(6)}$. Thyroid stimulating hormone in the first trimester of normal pregnancy there is an increase chariogenic hormone gonadotropin (hCG). Thyroid consequences on the hCG increase will cause a temporary increase in FT4 and T3 levels at the end of the first trimester (peak circulating hCG) and this will cause a decrease in basal TSH levels.

Serum TSH values decreased slightly in the first trimester of pregnancy is a response to an increase in hCG. In this study based on secondary data retrieval is known that pregnant women were examined TSHnya levels consisting of the first trimester, second and third, but mostly in the second trimester of pregnancy. Low birth weight babies may also be influenced by other factors, namely one that is examined in this study were maternal age and parity. Statistically maternal age has been associated with the incidence of LBW in Magelang District, the RR value of 2.96 and a p-value of 0:00. Showed a significant relationship between maternal age with LBW with $\mathrm{p}=0.01$ where $\mathrm{OR}=1.36(95 \% \mathrm{CI}: 1.08-1.73)$, meaning that the risk of respondents aged $<20$ years or $>35$ years is likely to give birth to low birth weight 1.36 times greater compared to respondents aged 20-35 years $(95 \% \mathrm{CI}=1.08 \text { to } 1.73)^{(7)}$.

The numbered of risk factors that can lead to low birth weight, but in this study only two were examined because of data limitations. Age of mother affects the baby weight in accordance with the theory that pregnant women with age <20 years of age maternal conditions that still need nutrients for growth biologiknya. The need for growth and the need for biological mother of the fetus in the womb is the fulfillment of two things takes place through a competitive mechanism, in which the fetus is in a state of the weaker party. This is why babies born with low weight. At a young age, the development of reproductive organs and physiological functions have not been optimal. In addition, emotional and mental state is not mature enough, so the mother during pregnancy has not been able to respond perfectly and frequent pregnancy complications.

In addition, the young age of pregnant women, there will be danger of infants born preterm, mild bleeding and the baby was born. Although pregnancy is very risky but under the age of pregnancy over the age of 35 years is not recommended because 
it is very dangerous. Given this age often begin emerging diseases such as hypertension, benign gynecological organs are aging and the content of the birth canal has rigid. The difficulties and dangers that will occur in pregnancy over the age of 35 years is preeclampsia, premature rupture of membranes, bleeding, delivery is not smooth and low birth weight ${ }^{(8)}$.

\section{CONCLUSION}

Statistically, there was no correlation between low TSH levels with LBW in Magelang District. Age mother who is outside variables have statistically significant relationship with the incidence of LBW in Magelang District. Pregnant women should be keeping and attention to health problems during pregnancy so as not to adversely affect the baby and health workers are also expected to further enhance the promotion of health of thyroid problems in pregnancy. Further research is needed about thyroid problems in pregnant women against the incidence or impact on the baby in Magelang District. Expected in the next researcher to examine hCG and FT4 to be able to control the factors that affect the levels of TSH.

\section{REFERENCES}

1. Cunningham, F.G., Leveno, K..J., Bloom, S.L., Haunth, J. C., Gillstrap III, L. C., Wenstrom, K. D. (Eds) (2005) William Obstetrics, $22^{\text {nd }}$ Edition. New York: MC Graw Hill.

2. National Institutes of Health, (2012) Pregnancy and Thyroid Disease, New York: U.S. Departemen of Healht and Human services

3. Clutter, W (2000), Endocrine diseases in clinical maternal-fetal medicine, New York: The parthenon publishing

4. Longcope, Chirsttopher, (1993), The Male and Female Reproductive Systems (dalam The Thyroid), Pennsylvania.

5. Millar, MD et all, (1994), Low Birth Weight and Preeclampsia in Pregnancies Complicated by Hyperthyroidism, The Division of Maternal-fetal Medicine, Department of Obstetrics and Hynecology, Los Angeles, pp. 0029-7844

6. Simarmata, O.S. (2010) Antenatal Care Quality Relationships Genesis Against Low Birth Weight Babies in Indonesia (Secondary Data Analysis Demographic and Health Survey of Indonesia, 2007), Thesis: Jakarta, University of Indonesia

7. Phoojaroenchanachai et all (2001) Effect of maternal hyperthyroidism during late pregnancy on the risk of neonatal low birth weight, Division of Endocrinology and Metabolism, Department of Medicine, Faculty of Medicine Siriraj Hospital, Mahidol University, Bangkok, Thailand.

8. Wiknjosastro, (2005) obstetrics, Jakarta: Bina Pustaka-Sarwono Prawirohardjo foundation. 